\title{
Magnocellular and Parvocellular Contributions to the Responses of Neurons in Macaque Striate Cortex
}

\author{
Tara A. Nealey and John H. R. Maunsell \\ Department of Physiology and Center for Visual Science, University of Rochester, Rochester, New York $14642-8642$
}

\begin{abstract}
Anatomical and physiological studies of the primate visual system have suggested that the signals relayed by the magnocellular and parvocellular subdivisions of the LGN remain segregated in visual cortex. It has been suggested that this segregation may account for the known differences in visual function between the parietal and temporal cortical processing streams in extrastriate visual cortex. To test directly the hypothesis that the temporal stream of processing receives predominantly parvocellular signals, we recorded visual responses from the superficial layers of $V_{1}$ (striate cortex), which give rise to the temporal stream, while selectively inactivating either the magnocellular or parvocellular subdivisions of the LGN. Inactivation of the parvocellular subdivision reduced neuronal responses in the superficial layers of $\mathrm{V}_{1}$, but the effects of magnocellular blocks were generally as pronounced or slightly stronger. Individual neurons were found to receive contributions from both pathways. We furthermore found no evidence that magnocellular contributions were restricted to either the cytochrome oxidase blobs or interblobs in V1. Instead, magnocellular signals made substantial contributions to responses throughout the superficial layers. Thus, the regions within V1 that constitute the early stages of the temporal processing stream do not appear to contain isolated parvocellular signals. These results argue against a direct mapping of the subcortical magnocellular and parvocellular pathways onto the parietal and temporal streams of processing in cortex.
\end{abstract}

IKey words: striate cortex, V1, LGN, magnocellular, parvocellular, macaque monkey]

The primate visual system contains two anatomically and physiologically distinct pathways that lead from the retina to area V1 (striate cortex). They arise from different retinal ganglion cell classes and segregate into the magnocellular and parvocellular subdivisions of the lateral geniculate nucleus (LGN), from which they derive the names $\mathbf{M}$ and $P$ pathways. Parallel organization also exists in higher visual cortex. The multiple visual areas in cerebral cortex form two distinct streams of processing that mediate the analysis of different types of visual information (Ungerleider and Mishkin, 1982; Van Essen and Maunsell, 1983;

\footnotetext{
Received June 27, 1993; revised Sept. 9, 1993; accepted Sept. 21, 1993.

We thank Peter Vamvakias for excellent technical assistance, and John Assad, Daniel Felleman, and Nikos Logothetis for critical comments on an early version of the manuscript. This research was supported by NIH R01EY05911 and a McKnight Foundation Development Award.

Correspondence should be addressed to John Maunsell, Division of Neuroscience, S-603, Baylor College of Medicine, One Baylor Plaza, Houston, TX 77030 Copyright $(\mathrm{C} 1994$ Society for Neuroscience $0270-6474 / 94 / 142069-11 \$ 05.00 / 0$
}

Maunsell and Newsome, 1987). A parietal stream is thought to be more important for spatial and motion processing, while a temporal cortical stream is thought to contribute primarily to the processing of color, form, and object recognition. Although these cortical streams are extensively interconnected and do not represent independent channels in the same strict sense as the subcortical $\mathrm{M}$ and $\mathrm{P}$ pathways, many lines of evidence suggest that the cortical streams are largely independent and distinct (see Merigan and Maunsell, 1993).

It has been suggested that the physiological and functional differences between the parietal and temporal streams can be attributed in part to differential contributions from the $M$ and $P$ pathways. Converging evidence from anatomical, physiological, and behavioral studies formed the basis of the proposal that the parietal stream is dominated by contributions from the $\mathrm{M}$ pathway, while the temporal stream is the recipient of information relayed by the P pathway (Livingstone and Hubel, 1987b; Maunsell, 1987). A link between the parietal stream and the $M$ pathway is based on general similarities in response properties (Motter and Mountcastle, 1981; Maunsell and Van Essen, 1983 ) and strong inputs to the parietal stream from layer $4 \mathrm{~B}$ in V1 (Lund et al., 1976; Livingstone and Hubel, 1987a), which is dominated by signals that arise from the $M$ pathway (Lund and Boothe, 1975). Recent experiments using selective inactivation of the magnocellular or parvocellular LGN have supported the idea that the parietal stream is dominated by $\mathrm{M}$ input (Maunsell et al., 1990): The responses of most neurons in the middle temporal visual area (MT), an important station in the parictal stream, are greatly reduced when the $M$ pathway is silenced. $P$ pathway inactivation has far less effect on responses in MT, although a minor contribution could be demonstrated in some neurons.

Whether the P pathway dominates the temporal stream in a complementary fashion is a more complicated issue. Anatomical and physiological observations suggest a major contribution from the $\mathrm{P}$ pathway to the temporal stream, but there is also evidence for M pathway contributions. For example, layers $4 \mathrm{C} \alpha$ and $4 \mathrm{~B}$ in $\mathrm{V} 1$, which are dominated by $\mathrm{M}$ pathway inputs, send substantial projections to more superficial layers (Blasdel et al., 1985; Fitzpatrick et al., 1985), which give rise to the temporal stream (see Fig. 1). Nevertheless, there has been the possibility that $\mathrm{M}$ pathway contributions might be limited to one subdivision of the temporal stream. The route between $\mathrm{V} 1$ and the temporal stream can be anatomically subdivided on the basis of patterns of cytochrome oxidase staining in V1 and V2. Signals from $\mathrm{V} 1$ reach the temporal stream either through the $\mathrm{V} 1$ blobs and V2 thin stripes, or else through the V1 interblobs and V2 interstripes (Horton and Hubel, 1981; Livingstone and Hubel, 
PARIETAL TEMPORAL

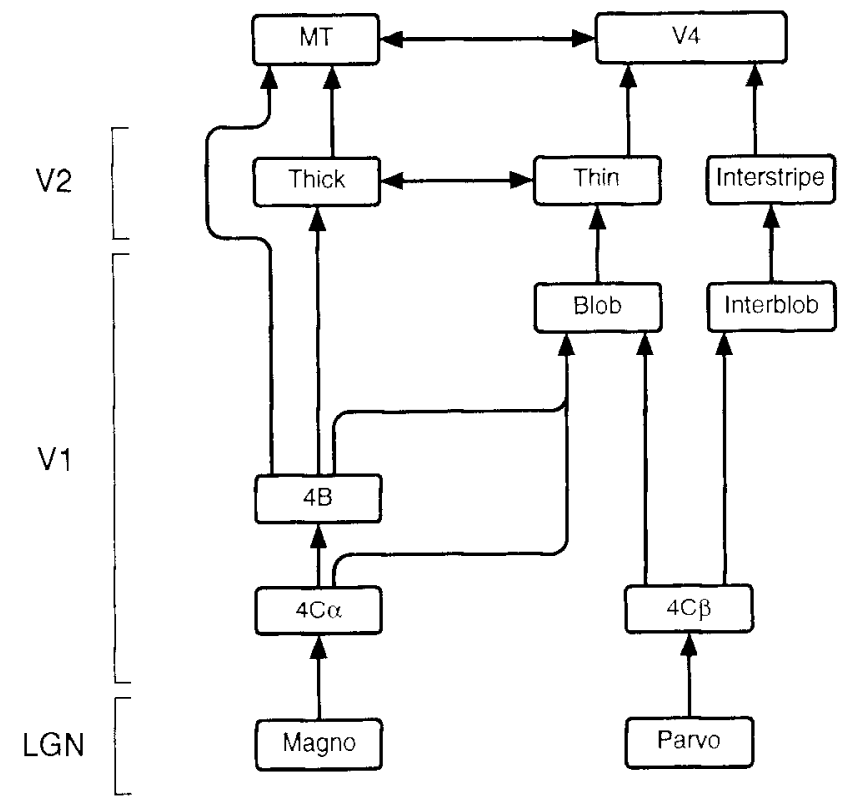

Figure 1. Pathways of the primate geniculocortical visual system. A subset of the known components and connections is shown. $M T$ and 14 are major elements in the parietal and temporal pathways. Up to the level of layer $4 C$ in $V l$, inpuls are sharply divided between the magnocellular and parvocellular pathways. In visual cortex anatomical connections exist both between different compartments of $\mathrm{VI}$ and $\mathrm{V} 2$ and between $M T$ and 14 .

1984a,b; Wong-Riley and Carroll, 1984; DeYoe and Van Essen, 1985; Shipp and Zeki, 1985; Hubel and Livingstone, 1987; see Fig. 1). If $M$ pathway contributions were confined to one subdivision of the temporal stream, then the other subdivision might contain a relatively pure $P$ pathway contribution.

Most workers have converged on the notion that M pathway contributions to the superficial areas of $\mathrm{V} 1$ are directed primarily to the cytochrome oxidase blobs (Hubel and Livingstone, 1987: DeYoe and Van Essen, 1988; Livingstone and Hubel, 1988a; Zrenner et al.. 1990) and have cited several lines of evidence: some neurons in the blobs have properties similar to type 4 neurons in the magnocellular layers of the LGN (Livingstone and Hubel, 1984a); blob neurons, like magnocellular neurons, are driven by low-contrast stimuli (Tootell et al., 1988); cytochrome oxidase blobs remain visible following destruction of the parvocellular layers of the LGN (Merigan and Eskin, 1986); and anatomical projections from layers $4 \mathrm{~B}$ and $4 \mathrm{C} \alpha$ project specifically to the blobs (Lachica et al., 1992). Collectively. these observations raised the possibility that the V1 blobs, and the $\mathrm{V} 2$ thin stripes to which they project, may receive mixed $\mathrm{P}$ and $M$ contributions, while the $V 1$ interblobs and $V 2$ interstripes maintain a relatively pure $P$ pathway signal (Fig. 1). Because the segregation established in the V/ blobs and interblobs and the $V_{2}$ thin stripes and interstripes appears to persist beyond the level of V4 (DeYoe and Sesola, 1991; Felleman and McClendon, 1991), a relatively pure $P$ pathway contribution might exist up to the highest levels of cortical processing in the temporal stream.

The validity of this view about contributions to the temporal stream remains to be established. The evidence that $M$ pathway contributions are restricted to the VI blobs and V2 thin stripes is not conclusive. The similarity between response properties in the cytochrome oxidase compartments and those in the LGN subdivisions cannot be used to draw firm conclusions about connectivity (see Hubel and Livingstone, 1990). While interlaminar connections in $\mathrm{Vl}$ show that $\mathrm{M}$ pathway contributions project primarily to the blobs (Lachica et al., 1992), they might reach the interblobs and thin stripes in V2 by indirect routes. There are many anatomical connections that might act to mix $\mathrm{M}$ and $\mathrm{P}$ channel contributions in the temporal pathway, some of which are shown in Figure 1, and subcortical and feedback connections may also mediate substantial mixing of $\mathrm{P}$ and $\mathrm{M}$ signals. For example, it is known that the fecdback projections to $\mathrm{Vl}$ from areas MT and $\mathrm{V} 4$ are generally not segregated according to cytochrome oxidase compartments (Krubitzer and Kaas, 1989).

We obtained more direct information on the $\mathrm{M}$ pathway contributions carly in the temporal stream by measuring the visual responses of cortical neurons before and after selectively blocking signals from either the $\mathrm{M}$ or $\mathrm{P}$ pathway. This can be done by taking advantage of the strict anatomical segregation of the $M$ and $P$ pathways at the level of the LGN, using the technique of selective inactivation (Malpeli and Schiller, 1979). In an earlier study, Malpeli et al. (1981) examined magnocellular and parvocellular contributions to neurons in VI using this approach. They found that many ncurons received mixed inputs, but the location of those neurons relative to layers and cytochrome oxidase compartments were not established. In this ar ticle we describe magnocellular and parvocellular contributions to responses in V1, with emphasis placed on the distribution of magnocellular contributions within the superficial layers. In a companion paper (Ferrera ct al., 1994) we examine magnocellular and parvocellular contributions in a later stage of the temporal pathway, area $V 4$.

Some of the results presented here have previously appeared in short reports (Nealey and Maunsell, 1991: Nealey et al., 1991: Ferrera et al., 1992; Maunsell e1 al., 1992).

\section{Materials and Methods}

Surgery and preparation for recording. Data were collected from eight macaque monkeys (four Macaca mulatta, three $M$. nemestrina and one M. fascicularis) that weighed between 2 and $10 \mathrm{~kg}$. Somc of these animals had been previously used in unrelated behavioral or neurophysiological cxperiments. Each animal was prepared for ncurophysiological recordings with initial doses of ketamine $(15 \mathrm{mg} / \mathrm{kg}, 1 . \mathrm{m}$.), atropine $(0.04 \mathrm{mg}$ $\mathrm{kg}, \mathrm{i} . \mathrm{m}$.) and diazepam $(0.25 \mathrm{mg} / \mathrm{kg}$ i.m. . A venous cannula was placed in a superficial leg vein and the trachea was intubated. The animal was then positioned in a stereotaxic frame. Surgical anesthesia was achicved with an infusion of sulentanil $(4-8 \mu \mathrm{g} / \mathrm{kg} / \mathrm{hr})$. A craniotomy and durotomy were made for a dorsal approach to the LGN in one hemisphere, and a craniotomy was made over $V 1$ in the same hemisphere using a $4 \mathrm{~mm}$ trephine, leaving the dura mater intact. Microdrives were positioned over the craniotomies, which were then filled with moist Gelfoam and covered with warm agar. The V1 microdrive was positioned for penetrations normal to the cortical surface to minimize shifts in receptive field location as the clectrode advanced. Additional VI craniotomies were made as needed during the experiment.

When surgery was complete, the animal was paralyzed (vecuronium bromide. $25 \mu \mathrm{g} / \mathrm{kg}$, i.v., followed by infusion at $100 \mu \mathrm{g} / \mathrm{kg} / \mathrm{hr}$ ) and respired with room air to maintain end-tidal $\mathrm{CO}_{2}$ near $32 \mathrm{~mm} \mathrm{Hg}$. Anesthesia was maintained with an infusion of sufentanil at the rate previously established to produce sutgical anesthesia. Body temperature was maintained with a thermostatically controlled heating blanket. ECG, heart rate, end-tidal $\mathrm{CO}_{2}$, and rectal temperature were all continuously monitored throughout the experiment. Ophthalmic atropine $(1 \%)$ was administered to obtain cycloplegia and mydriasis. Chloromycetin $(0.5$ $\mathrm{mg}$, i.m.) was administered every $12 \mathrm{hr}$ as prophylactic antibiotic. Gas- 
permeable contact lenses were fitted to protect the corneas, and spectacle lenses were used to refract the eyes onto a tangent screen $114 \mathrm{cml}$ in front of the animal.

Neurophysiological recordings. Microelectrode recordings were made simultaneously in V1 and the LGN. Recordings in Vl employed microelectrodes made of glass-insulated, etched Pt-Ir wire, with an impedance of $1-2 \mathrm{M} \Omega$ at $1 \mathrm{kHz}$. LGN recordings were made using a recording/injection probe in which an etched Pt-Ir wire extended 20$50 \mu \mathrm{m}$ out of a glass micropipette whose tip had been ground to an outer diameter of $20-60 \mu \mathrm{m}$. The barrel of the recording/injection probe was filled with a solution of $25 \mathrm{~mm} \gamma$-aminobutyric acid (GABA), an inhibitory neurotransmitter, in sterile saline. This solution could be pressure injected from the tip. Single-unit or multiunit signals from the V1 microelectrode and multiunit signals from the LGN recording/injection probe were separately amplified, filtered, and monitored on an oscilloscope and audio monitor. Signals from both sites were digitized using window discriminators and collected with a $1 \mathrm{msec}$ resolution by computer. Multiunit recording sites in $\mathrm{V} 1$ were separated by a minimum of $200 \mu \mathrm{m}$, and electrolytic marking lesions ( $5 \mu \mathrm{A} \times 5 \mathrm{msec}$ ) were made at selected sites to aid in the histological reconstruction of electrode tracks.

Recording proceeded as follows. A responsive single-unit or multiunit V1 site was first located by advancing the microelectrode in the region of the calcarine sulcus where eccentricities beyond $17^{\circ}$ are represented. Receptive fields for the left and right eyes were plotted on the tangent screen using a hand-held projector, and the orientation preference and ocular dominance were judged by listening to neuronal activity over the audio monitor. If a sufficiently strong response was driven through the contralateral eve, the $\mathrm{LGN}$ recording/injection probe was moved to the retinotopically corresponding representation in one of the LGN layers, guided by the map of Malpeli and Baker (1975). Identification of LGN layers was made on physiological criteria including the characteristic alternation of contralateral and ipsilateral eye input between successive layers and differences in temporal characteristics of the responses between magnocellular and parvocellular neurons (Schiller and Malpeli, 1978). V1 and LGN receptive fields were considered sufficiently well aligned when their centers were within about $0.5^{\circ}$. At the eccentricities studied (average eccentricity, $21^{\circ}$ ) the magnification factor in LGN layer 6 is approximately $110 \mu \mathrm{m} /$ degree, and in layer 1 is approximately $70 \mu \mathrm{m} /$ degree (Connolly and Van Essen, 1984). The tip of the LGN probe was thercforc within $100 \mu \mathrm{m}$ of the point where receptive fields would be perfectly aligned. Once the receptive fields were aligned, impulses from the $V 1$ site were collected first in the absence of visual stimulation, and then during $2 \mathrm{~min}$ of visual stimulation. While the stimulation continued, 75-125 $\mathrm{nl}$ (usually $100 \mathrm{nl}$ ) of the GABA solution was then injected into the LGN layer. The quantity injected was determined by measuring the movement of the meniscus within the previously calibrated glass barrel of the pipette. Signals from both the LGN injection site and the V1 site were recorded for at least 10 min after the injection, after which activity was again recorded in the absence of a visual stimulus.

Although we used lidocaine and $\mathrm{Mg}^{2+}$ as blocking agents in a previous study (Maunsell et al., 1990), GABA offers several advantages. Unlike lidocaine, it does not affect fibers of passage, and its effects are more reversible than those of $\mathrm{Mg}^{2+} . \mathrm{GAB} \Lambda$ receptors are abundant in both the magnocellular and parvocellular layers of the LGN (Shaw and Cynader, 1986). The spatial extent of inactivation resulting from injecting GABA was determined in control experiments in which a second microelectrode was positioned in the LGN at successively greater distances from the tip of the recording/injection probe. Figure 2 shows the spread of the effects from $100 \mathrm{nl}$ injections of GABA. At the injection center responses to a flashing spot were completely blocked for about $2 \mathrm{~min}$, and recovered slowly and incompletely. Responses $0.5 \mathrm{~mm}$ away were also abolished for about $1-2$ min, but showed more rapid recovery. No clear effects of the injection were observed at distances of 1.0 and 1.5 $\mathrm{mm}$ from the center of the injection. These measurements and other controls involving recording from two probes in the LGN during GABA injections (Ferrera et al., 1994) demonstrated that the direct effects of the injection were highly localized.

Vistual stimulation. All visual stimuli were created on a color video monitor ( 57 or $60 \mathrm{~Hz}$, noninterlaced). The aligned receptive ficlds for the LGN and V1 were positioned on the face of the monitor using a large front-surface mirror placed immediately in front of the animal. The monitor displayed bars whose color, length, width, orientation, direction, speed, and excursion could all be varied under joystick or computer control. Luminance for white stimuli was $80 \mathrm{~cd} / \mathrm{m}^{2}$ on a

\section{GABA INJECTIONS}

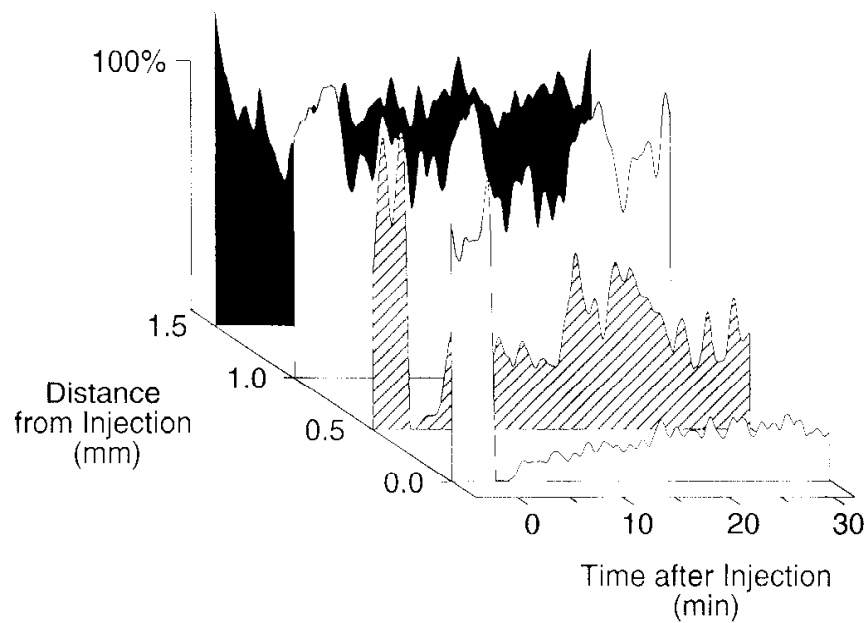

Figure 2. The spread of the effects of $100 \mathrm{nl}$ injections of GABA in the LGN. Each histogram represents the visual response in the LGN recorded at different distances from the injection site. The $x$-axis represents time relative to the time of injection, and the $y$-axis represents the response normalized to its average response during $4 \mathrm{~min}$ immediately preceding the injection. The $z$-axis represents distance from the injection site. The histogram at $0.0 \mathrm{~mm}$ was obtained after aligning the electrode and injection probe based on receptive field location and depth within the given layer of the LGN. This method brought the tips of the two electrodes to within an estimated $100 \mu \mathrm{m}$ of each other. The histograms at greater distances were obtained by advancing the electrode beyond the zero point.

background of $0.2 \mathrm{~cd} / \mathrm{m}^{2}$, and luminances for red, green, and blue stimul were 18,55 , and $12 \mathrm{~cd} / \mathrm{m}^{2}$. Stimulus size, orientation, color, and speed were adjusted to optimize the cortical response at each recording site. It was clear from the LGN recordings that both parvocellular and magnocellular neurons were strongly driven by the stimuli uscd.

Stimulus size and movement were constrained so that the stimulus remained within $1^{\circ}$ of the center of the LGN receptive field. This was done to ensure that the entire representation of the stimulus in the injected LGN layer was blocked. Flashing stimuli were bars no greater than $1^{\circ}$ on a side delivered with a $50 \%$ duty cycle and a period of $1-3$ sec. Moving stimuli were optimally oriented bars that swept back and forth across the receptive field at 1-8 degrees/sec over an excursion of less than $1^{\circ}$. Usually the moving stimuli paused briefly at the end of each traverse.

During data collection only the contralateral eye was stimulated, and recordings were always made at eccentricities beyond $17^{\circ}$. In the macaque LGN, the central visual hemifield is represented by six layers, four parvocellular and two magnocellular. However, the portion of the LGN that represent eccentricitics beyond about $17^{\circ}$ contains only four layers, two parvocellular and two magnocellular. In this region contralateral stimulation activates only the dorsal parvocellular layer and the ventral magnoccllular layer, leaving a buffer of two inactive layers between. This approach made it possible to block the representation completely and selectively in either the magnocellular or parvocellular subdivision without affecting the stimulus representation in the other. Data are also reported from two experiments in which two injection probes were located in the LGN, one in the contralateral parvocellular layer and one in the magnocellular layer.

Data analysis: The effects of selective LGN inactivation on cortical responses were analyzed with a method similar to that used in a previous study (Maunsell et al., 1990). Changes in cortical response following LGN inactivation were quantified using a blocking index (BI), which compared visual responses before and after LGN block. Pre- and postinjection responses were computed by separately averaging the cortical responses to the 50 stimulus cycles immcdiately before the injection period and the responses to the 50 stimulus cycles immediately after the injection period (Fig. 3). The resulting histograms were smoothed 


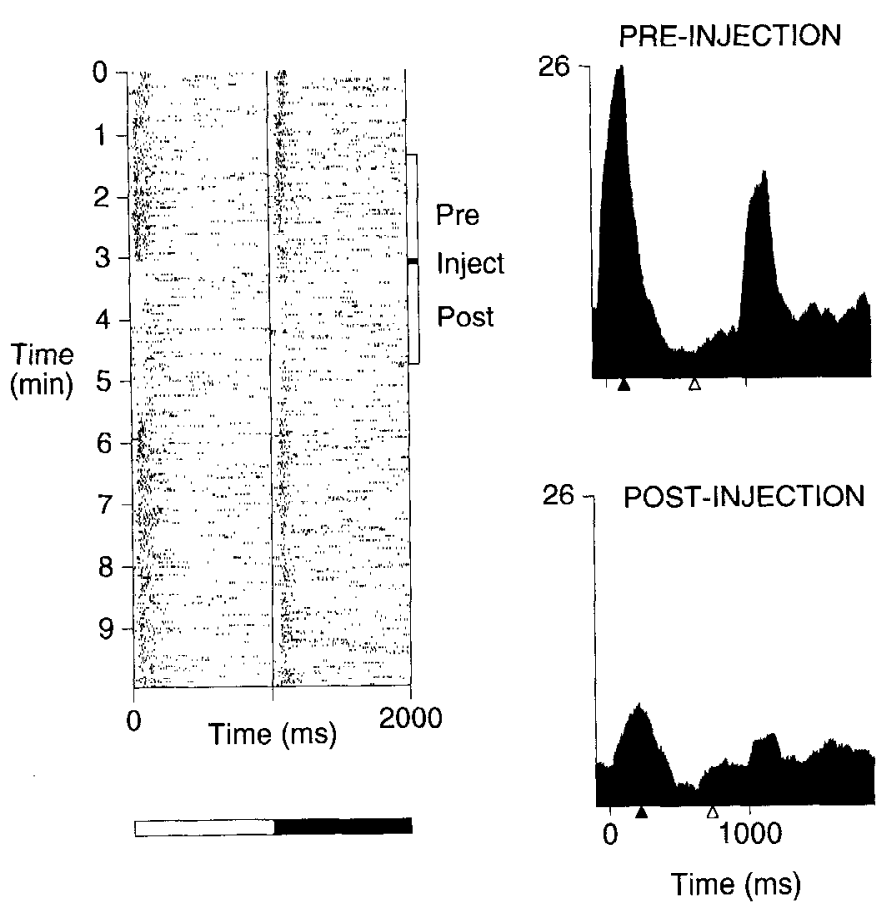

Figure 3. Effects of magnocellular LGN block on responses of a single unit in the superficial layers of $\mathrm{V} 1$. The left half shows a raster display of the V1 activity recorded in response to a flashing white bar. The stimulus cycle lasted 2000 msec, with the bar on during the first half of the cycle, as indicated by the open and solid rectangles at the bottom. Each horizontal line in the raster represents one stimulus cycle, with successive stimulus cycles appearing further down in the plot. The right side of the raster plot is marked to indicate the periods during which pre- and postinjection responses were compiled (open bars), and the brief period during which $100 \mathrm{nl}$ of GABA solution was made into magnocellular LGN layer I (solid bar). The average responses during the pre- and postinjection periods are plotted as smoothed histograms in the right panels. Small solid and open triangles under the histograms mark the bins corresponding to the peak and trough of response for the preinjection histogram. The timing of the peak and trough in the preinjection histogram were used in computing the response during both the pre- and postinjection periods. These in turn served as the basis for the blucking index. Because the smoothing process spreads responses by as much as $1 / 20$ th of the stimulus cycle, the phase of the stimulus cycles in the histograms in this and other figures has been shifted slightly (as reflected by the offset placement of time 0 ) so that the first peak in the response does not extend beyond the left end of the histogram and wrap around onto the right side. The block of magnocellular LGN activity greatly reduced the responses of this unit. The blocking index (BI) computed for this unit was 0.82 .

by boxcar averaging using an averaging length of $1 / 10$ of the stimulus period. In order to include both excitatory and inhibitory modulation of activity, we based response measurements on the difference between the peak and trough in the pre- and postinjection histograms (solid and open triangles in Fig. 3). Recause noise in the histogram increases the difference between the peak and trough, the response was taken to be the difference between the peak and trough minus a baseline peak/trough difference determined from activity sampled in the absence of a stimulus. The BI was then calculated as 1.0 - (postinjection response/ preinjection response). A value of 0.0 represents no block, and 1.0 represents a complete block. This BI is negative when the response increases following LGN block, and can exceed 1.0 if the difference between the peak and trough in the postinjection histogram was less than the peak/trough difference in the absence of a visual stimulus.

The choice of 50 stimulus cycles as the basis for pre-and postinjection responses represents a compromise; using fewer trials leads to greater variability in the measurements, whereas using more trials can extend beyond the period of complete LGN block. Tests in which we analyzed data using longer or shorter periods had the expected effects on the mean and variance of the BI measures, but did not substantially alter any of the results reported here. The duration of complete LGN block was generally $1-2 \mathrm{~min}$ (Fig. 2), and longer than the duration of 50 stimulus cycles. Occasionally LGN responses began to recover during the sampling period, leading to an underestimate of the effects of the block (e.g., Fig. 8), but the contribution of occasional early recovery of LGN responses was small compared to the effects reported here.

The precision of BI measurement is affected by several factors, such as spontaneous changes in cortical responsivity during the measurement period. An indication of the variability of BI measurements can be obtained from recordings made in layers $4 \mathrm{~A}$ and $4 \mathrm{C}$, which should be completely dominated by either magnocellular or parvocellular inputs. Of the $10 \mathrm{BI}$ determinations made in these layers (presented below), the BIs were distributed around the expected value (either 0 or 1 ) with a standard deviation of 0.23 . It is likely that noise from various sources contributes this degree of uncertainty to all BIs described here. Further consideration of the interpretation and limitations of the BI is taken up in the Discussion.

Histological reconstruction. At the end of the recording session, the animal was given an overdose of sodium pentobarbital and perfused with a phosphate buffer rinse $(\mathrm{pH} 7.4)$ followed by $4 \%$ paraformaldehyde solution, $4 \%$ paraformaldehyde with $10 \%$ sucrose, and finally phosphate buffer with $10 \%$ sucrose. The brain was removed, blocked and equilibrated with $30 \%$ sucrose in phosphate buffer. An occipital block containing the V1 recording sites was cut on a freezing microtome in parasagittal sections $60 \mu \mathrm{m}$ thick. Sections were reacted for the cytochrome oxidase activity using a cobalt-intensification protocol (Silverman and Tootell, 1987).

Enlargements of the mounted, stained sections were used to mark the locations of V1 sites based on electrolytic lesions and microdrive depth readings. For determination of the cytochrome oxidase staining pattern in V1, tracings of sections were made using a projection microscope. Darkly staining regions in the superficial layers were traced to locate the center of blobs. Blobs were not counted if they did not appear on three or more adjacent sections. The distances of superficial V1 sites from the nearest blob center were then measured. The nearest blob center was determined by taking into account the distance of the VI site both within and across the plane of the sections. The precision in measuring distance perpendicular to the plane of sectioning was limited by the $60 \mu \mathrm{m}$ thickness of the sections.

\section{Results}

\section{Magnocellular and parvocellular contributions to V1 superficial layers}

The first question addressed in these experiments was whether an appreciable contribution from the $\mathrm{M}$ pathway is evident in the responses of neurons in layers 2 and 3 of V1.V1 recordings obtained during selective blocks of the magnocellular LGN show that many neurons in superficial $\mathrm{V} 1$ do receive a clear, and in many cases a strong, contribution from the $\mathrm{M}$ pathway. Responses recorded from an isolated unit in the superficial layers of $\mathrm{V} 1$ before and after an injection of GABA into magnocellular layer 1 in the LGN are illustrated in Figure 3. This unit was tested with a flashing bar and responded with a transient burst of impulses when the bar flashed on or off. The cortical response was greatly reduced when GABA was injected into layer 1 , and then gradually recovered over a few minutes as the effects of the GABA wore off. The reduction in the cortical response is seen clearly in the preinjection and postinjection average response histograms in the right panels. The BI for this site was 0.82 .

Magnocellular contributions were common in superficial V1. Fifty-three single- or multiunit recording sites were tested with magnocellular blocks and subsequently histologically localized to the superficial layers. The distribution of their BIs is plotted in Figure $4 A$. The median value was 0.37 , indicating that blocking magnocellular activity in the LGN on average eliminated over a third of the response at superficial V1 sites. About half ( 25 of 53 ) of these sites were isolated units, and the distribution for their blocking indices is plotted in Figure $4 B$. There was no 
A

All Sites

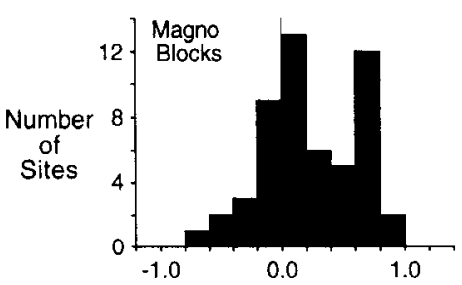

C

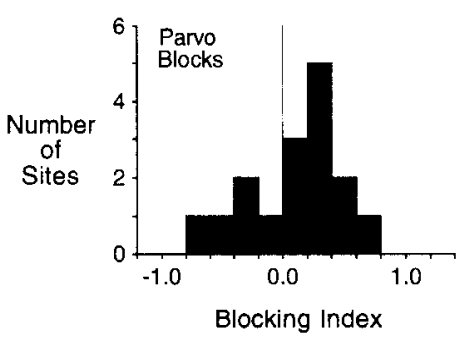

B

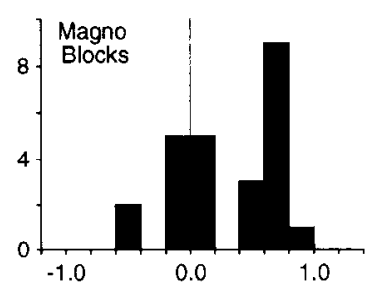

D

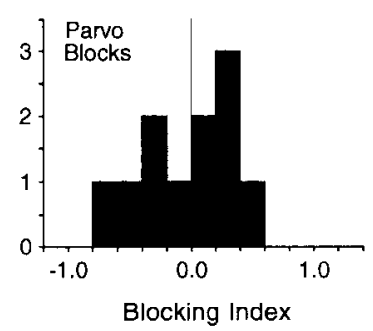

Figure 4. Distributions of magnocellular and parvocellular blocking indices for superficial V1 sites. Magnocellular blocking indices are in $A$ and $B$; parvocellular are in the $C$ and $D . A$ and $C$ plot data from all sites tested; $B$ and $D$ are the subsets of single-unit recording sites. The median BI for magnocellular inactivations was 0.37 , which was not significantly different than the median parvocellular BI of 0.39 (MannWhitney test, $p>0.42$ ). There was a larger difference betwecn the singlcunit median BIs for the magnocellular $(0.63)$ and parvocellular $(0.22)$ blocks, but this was also not significant $(p>0.06)$.

significant difference between the medians of the isolated units and multiunit sites when tested with magnocellular blocks (MannWhitney test, $p>0.28$ ).

Because we were primarily interested in magnocellular contributions, only 16 sites in the superficial layers were tested for parvoccllular contributions. As expected, most parvocellular blocks also produced obvious effects on the $\mathrm{V} 1$ responses, but these effects were generally not strong. Figure 5 shows the result obtained from a superficial V1 unit tested with parvocellular blockade. The BI for this unit (0.36) was close to the median for all superficial sites tested with parvocellular blockade (0.39). The distribution for the 16 superficial V1 sites tested with parvocellular blockade is illustrated in Figure $4 C$. Eleven of these sites were single units and the distribution of the BIs for these is presented in Figure $4 D$. There was no significant difference between the median BIs of the isolated units and multiunit sites when tested with parvocellular blocks (Mann-Whitney test, $p$ $>0.07)$.

These results do not suggest that the superficial layers are strongly dominated by either $\mathrm{M}$ or $\mathrm{P}$ pathway contributions. Both appear to provide an appreciable portion of the excitatory drive to superficial neurons. The failure of parvocellular inputs to dominate can be viewed as surprising, given that there are about eight times as many parvocellular-projecting retinal ganglion cells as magnocellular projecting (Perry et al., 1984). Median BIs were nevertheless comparable for magnocellular and parvocellular blocks, and some of the strongest effects resulted from magnocellular blocks. These results are consistent with the earlicr results of Malpcli ct al. (1981), who found that many cells in monkey striate cortex received appreciable excitatory drive from both LGN subdivisions.

The distributions of magnocellular BIs in Figure 4, $A$ and $B$,

\section{Parvo Block Bl: 0.36}
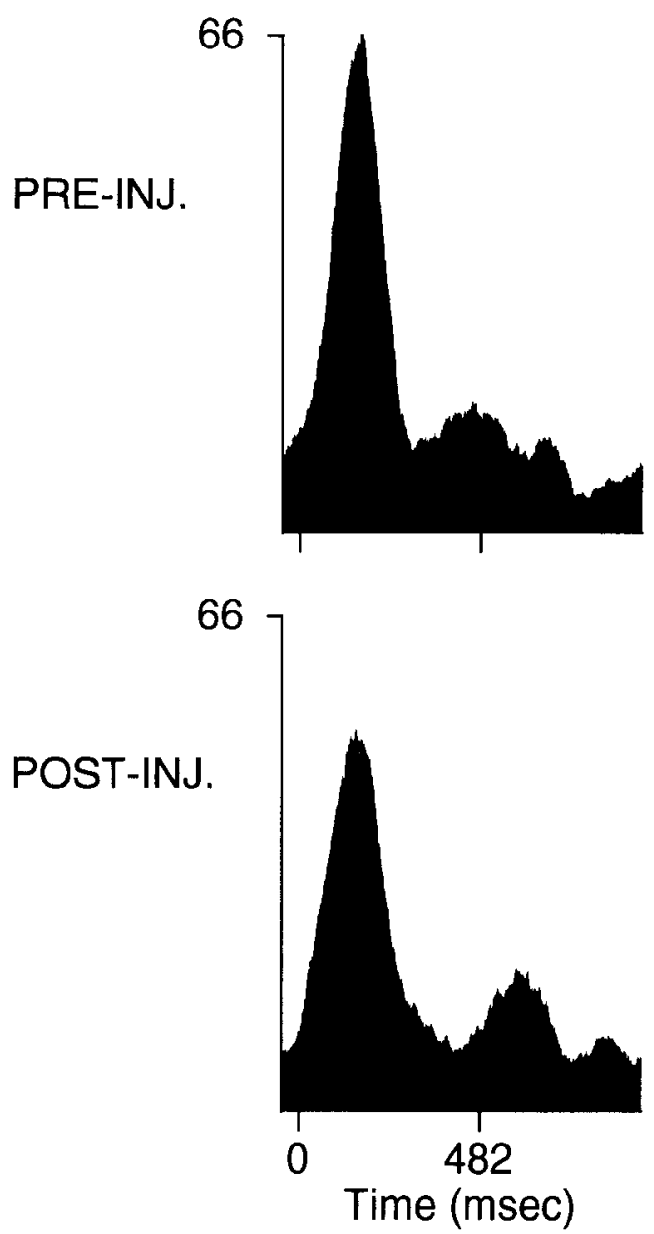

Figure 5. Effects of parvocellular block on a single unit in superficial V1. The upper panel shows the preinjection response histogram, and the lower panel shows the response histogram after injection of $125 \mathrm{nl}$ of GABA into the single active parvocellular layer. The stimulus was a flashing bar. The parvocellular block produced only a partial reduction of the cortical response. The blocking index $(B I)$ was 0.36 .

have hints of peaks near 0 and near 1 , corresponding to no effect and complete elimination of response. A bimodal distribution of this sort would imply that magnocellular and parvocellular contributions might be segregated on a local scale. To examine the question of whether individual neurons in superficial V1 receive substantial contributions from both the $M$ and $P$ pathways, in two experiments we inserted two injection probes into the LGN, one into the magnocellular subdivision and the other into the corresponding visual field representation in the parvocellular subdivision. Results from one cell that was tested in this way are illustrated in Figure 6. Individually, magnocellular and parvocellular blocks each produced clear, but incomplete, reductions of the cortical response (BIs of 0.26 and 0.57 ). Simultaneous block of both magnocellular and parvocellular LGN effectively abolished the cortical response (Fig. 6C, BI = 0.92).

Thirteen superficial sites in $\mathrm{Vl}$ were tested for the effects of first one type of L.GN block and then the other. Figure 7 shows the relationship between the magnocellular and parvocellular 
A: Magno Block B: Parvo Block C: Paired Block
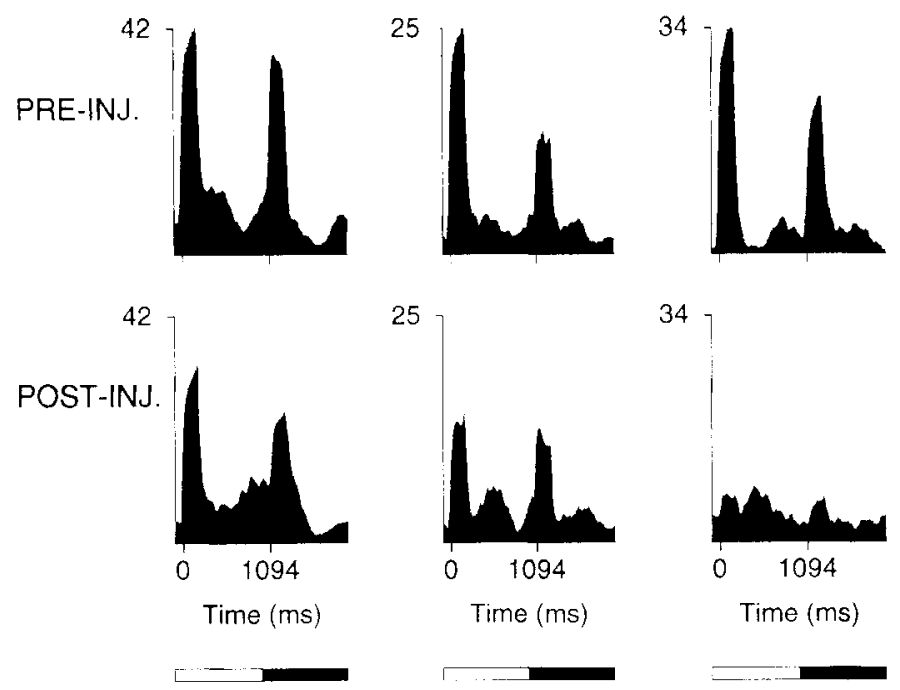

25

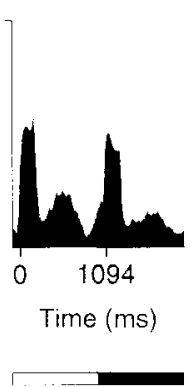

34

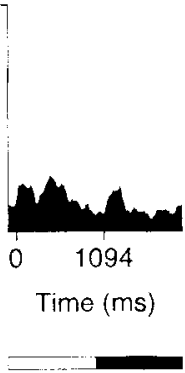

Figure 6. Effects of LGN blocks on a superficial V1 unit tested with magnocellular, parvocellular and paired blocks. Fach pair of hisiograms represents the unit's responses to a flashing bar before and after block of the selected LGN layer(s). $A$, Injection of GABA (100 nl) into magnocellular layer $1 ; \mathrm{Bl}, 0.26 . B$, Injection of $\mathrm{G} \wedge \mathrm{B} \wedge(125 \mathrm{nl})$ into the single active parvocellular layer; $B I, 0.57$. C. Simultaneous injections of $100 \mathrm{nl}$ of GABA into the magnocellular and parvocellular layers; $\mathrm{BI}$, 0.92. Each pair of plots is sealed to the peak of the preinjection histogram. The preinjection response at this and other sites varied from test to test owing to spontancous changes in responsivity and, in some cases, incomplete recovery from the effects of previous injections.

BIs for these sites. While there is no strong ncgative correlation between the BIs, sites with the strongest magnocellular BIs were among those with the weakest parvocellular indices, and vice versa. Most sites had responses that were partially reduced by either magnocellular or parvocellular blockade.

The failure to find a parvocellular dominance raises the question of whether GABA injections in the parvocellular LGN produce less complete blocks than those in the magnocellular subdivision. We think this is not the case for several reasons. Direct measurements of the spread of effects in the parvocellular LGN, together with established measurements of magnification factor indicate that a region much larger than the size of VI receptive fields was blocked by parvocellular injections (see Materials and Methods). Furthermore, parvocellular injections did eliminate responses at some sites. For example, Figure 8 shows responses from a multiunit recording site in layer $4 C \beta$ for which a parvocellular block essentially eliminated responses. In those cases where a parvocellular block was paired with a magnocellular block, responses were similarly eliminated (Fig. 6). We therefore believe that LGN injections provide an accurate picture of magnocellular and parvocellular contributions to excitatory drive in V1.

\section{Distribution of $L G N$ contributions relative lo cytochrome oxidase activity}

The distribution of $\mathrm{M}$ and $\mathrm{P}$ pathway contributions relative to the cytochrome oxidase blobs was examined by determining the distance of $\mathrm{V} 1$ recording sites from the nearest blob center. We prefer this approach over assigning sites as either inside or outside a blob because it remains to be determined whether the blobs and interblobs are discrete subdivisions, or if instead prop-

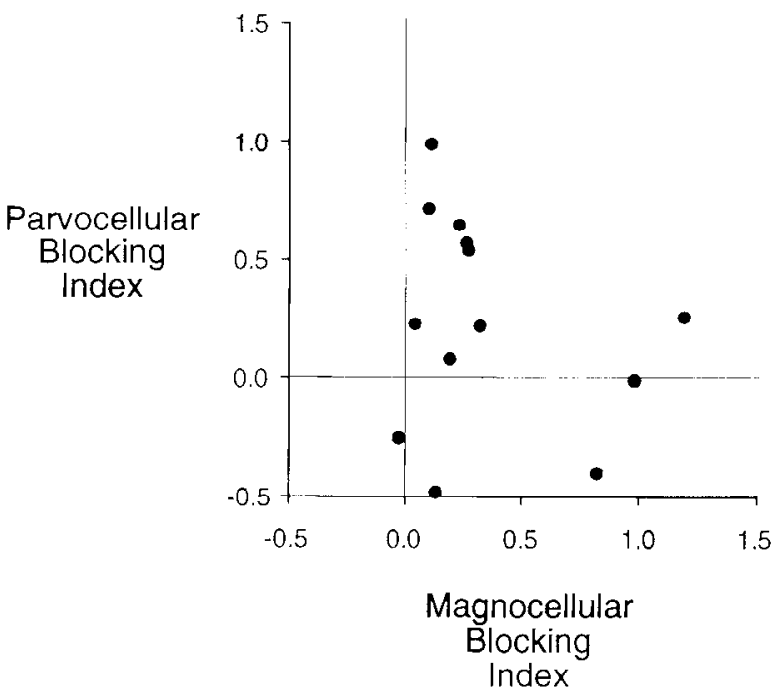

Figlure 7. Relationship between magnocellular and parvocellular blocking indices for superficial VI individual ncurons. The blocking indices are plotted for all cells that were tested with both magnocellular and parvocellular block. All injections were made in the four-layered part of the LGN. Units with the strongest magnocellular contributions tended to have the weakest parvocellular contributions, and vice versa.

erties vary continuously from blob like to interblob-like moving from the center of blobs to the center of interblobs. Blob borders are not sharp in histological sections and are not marked by interruptions of axonal or dendritic arborizations (Hübener and Bolz, 1991; Malach, 1992), nor is there compelling evidence for an abrupt physiological transition at blob borders.

Histological reconstruction provided the distance from the ncarest blob center for 50 superficial V1 sites that had been tested with LGN blockade. Figure 9 shows a V1 section that was stained for cytochrome oxidase activity. An electrode track can be seen passing through the banks of the calcarine sulcus, and two elcctrolytic lesions are visible near the end of the track (large arrows). Because it was difficult to evaluate cytochrome oxidase staining in the vicinity of lesions, we made lesions only in parls of the sulcus where no recordings were made. In the section shown, recordings were made as the electrode passed through two banks of the sulcus (upper right), and marking lesions were made after it passed on to the antcrior bank. In this case the electrode passed through blobs in both of the banks where recordings were made, although examination of neighboring sections was necessary to determine this with certainty. Because histological artifacts around the electrode track sometimes interfered with identification of blob borders, blobs were considered positively identified only when a matching staining pattern was observed on three successive sections. Sites for which no blob existed within $400 \mu \mathrm{m}$ were not used in this analysis on the assumption that the nearest blob was missing.

The histological analysis showed that $M$ pathway contributions are not sharply segregated between the blobs and interblobs. The BIs of the histologically identified sites tested with $\mathrm{M}$ or $\mathrm{P}$ pathway blocks are plotted against distance from the nearest blob center in Figure 10. Regression analysis showed no significant dependency of $\mathrm{BI}$ on distance from blob center for cither magnocellular blocks $(p>0.28$ ) or parvocellular blocks $(p>0.94)$, although magnocellular effects were slightly weaker near blob centers, particularly for single units (solid circles). 
Some VI neurons recorded close to a blob center were virtually silenced by magnocellular blocks, however. One such unit, tested with both magnocellular and parvocellular blockadc, is illustrated in Figure 11. Most of the cxcitatory drive for this unit depended on M pathway input (magnocellular BI $=0.98$, parvocellular $\mathrm{BI}=-0.04$ ). Other responses recorded near blob centers demonstrated more balanced inputs, such as those in Figure 6, which were recorded from a unit that was about 75 $\mu \mathrm{m}$ from a blob center.

Data on the distribution of parvocellular contributions relative to the cytochrome oxidase blobs were oblained only from two electrode penetrations. By chance, both these penetrations passed through cortex near the center of blobs. As a result, the points in Figure $10 B$ are restricted to the left half of the distance axis, and do not provide complete information about the overall distribution of $\mathrm{P}$ pathway contributions. They nevertheless show that some units near the center of blobs do not depend greatly on $P$ pathway input.

\section{Magnocellular contributions in deeper layers}

A limited number of recordings sites were in layers 4,5 , and 6 in V1. Figure 12 shows a plot of magnocellular BIs versus layer in cortex for 72 sites that could be unequivocally assigned to a layer. Nineteen of these sites were below layers 2 and 3 . While the data are too sparse to support strong conclusions, they are consistent with several expectations. The parvocellular-recipient layers $4 \mathrm{~A}$ and $4 \mathrm{C} \beta$ had miagnocellular blocking indices close to 0 , while the two sites recorded in layer $4 \mathrm{C} \alpha$ had values near 1. Layer $4 \mathrm{~B}$, which receives inputs from layer $4 \mathrm{C} \alpha$ ( $\mathrm{I}$ und and Boothe, 1975; Lund et al., 1979), also contains some strong magnocellular contributions. Layer 5 , which contains the neurons that project to the superior colliculus, was found to contain clear magnocellular inputs, as has been previously shown (Schiller et al., 1979). Finally, the only unit that was recorded in layer $6 \mathrm{~B}$ was more influenced by magnocellular block than were sitcs in layer $6 \mathrm{~A}$, which is consistent with the selective feedback projections from these sublaminae to the two LGN subdivisions (Lund and Boothe, 1975; Fitzpatrick and Einstein, 1989).

\section{Discussion}

Magnocellular contributions to the superficial layers of $\mathrm{VI}$. The principal finding of this study is that magnocellular layers of the LGN make a substantial contribution to the visual responses of neurons in the superficial layers of macaque V 1 . Results from several other studies suggested that this should be the case. Anatomical experiments have shown that the magnocellularly dominated layers $4 \mathrm{C} \alpha$ and $4 \mathrm{~B}$ both send direct axonal projections to the superficial layers (Blasdel et al., 1985; Fitzpatrick et al., 1985; Lachica et al., 1992). An carlier selective LGN inactivation experiment by Malpeli et al. (1981) showed that many simple cells and about a third of the complex cells in macaque $\mathrm{V} 1$ receive convergent excitatory input from both parvocellular and magnocellular LGN. Although the laminar position of those neurons was not determined in that study, the fact that the superficial layers make up about half the thickness of striate cortex makes it likely that many of the neurons recorded were superficial.

We found little evidence that magnocellular and parvoccllular inputs were appreciably segregated in the superficial layers, either between different neurons or between the blobs and interblobs. Individual neurons in the superficial layers that were tested with both magnocellular and parvocellular blockade for

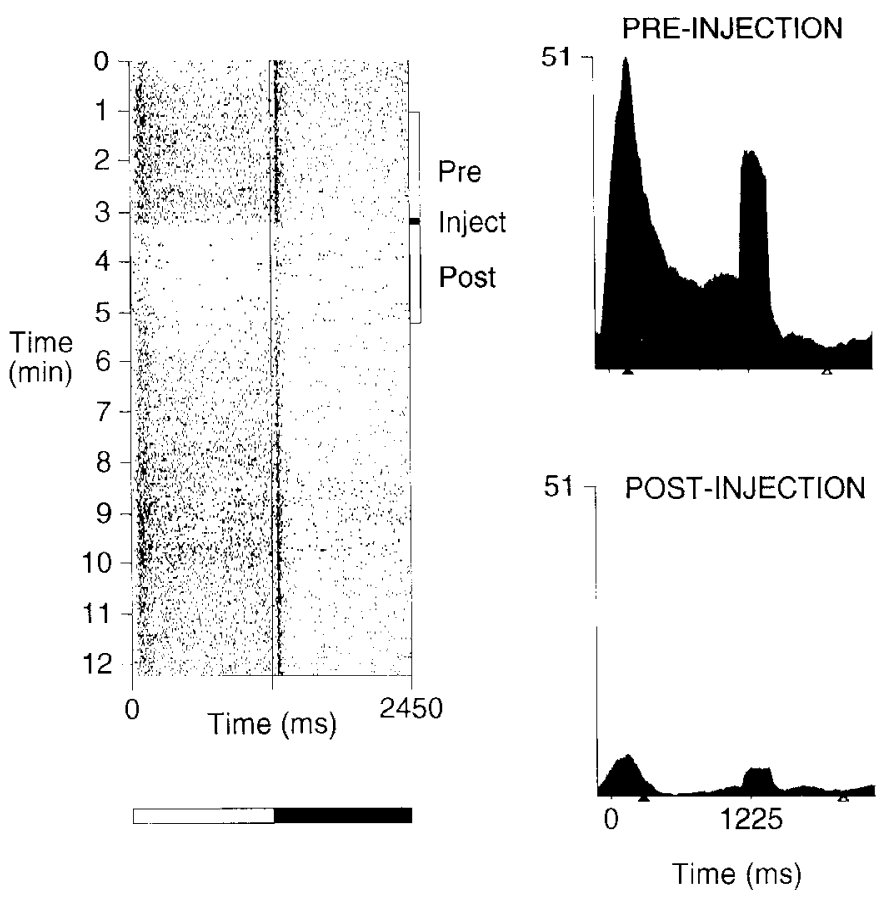

Figure 8. Responses of a multiunit site in layer $4 \mathrm{C} \beta$ before and after parvocellular block. The format of this figure is the same as for Figure 3. An injection of $100 \mathrm{nl}$ of GABA solution was made into the single active parvocellular layer at the lime marked Inject. The injection essentially eliminated the response to a flashing bar (BI, 0.98). The small remaining response in the postinjection histogram probably depends on the relatively fast recovery of response at this site. Because this was a multiunit site, it is also possible that the response may arise from fibers of passage going to layer $4 \mathrm{C} c$. The absence of a response in this layer following parvocellular injections shows that the inactivation method was adequate for removing parvocellular inputs to cortex.

the most part received contributions from both channels. The strength of magnocellular effects was comparable between blob and interblob regions. This observation is at odds with earlier reports that magnocellular contributions might be preferentially distributed to the cytochrome oxidase blobs. Nevertheless, there is no outright inconsistency between the present results and expectations from earlier studies. A magnocellular contribution to the interblobs is not precluded either by the existence of anatomical connections that direct magnocellular inputs to the blobs or by indications of magnocellular properties in the responses of blob neurons. A wealth of intra- and interlaminar connections within V1 (Hubel and Wiesel, 1972; Hendrickson et al., 1978; Blasdel and Lund, 1983; Fries, 1986; Payne and Peters, 1989; Lachica et al., 1992) could provide magnocellular inputs to the interblobs. Comparatively little is known about the termination patterns of feedback connections from extrastriate areas, but they might contribute as well. Similarly, the preferential activation of blobs by low-contrast visual stimuli (Tootell et al., 1988) need not depend on magnocellular inputs (see Watson, 1992: Merigan and Maunsell. 1993), and would not rule out less conspicuous magnocellular contributions to the interblobs.

On the other hand, results from inactivation experiments must be interpreted cautiously (see Maunsell et al., 1990). Response measurcments were made using a single, optimized visual stimulus, leaving open many questions about the role of $\mathrm{M}$ and $\mathrm{P}$ pathway contributions under different conditions, such as at 


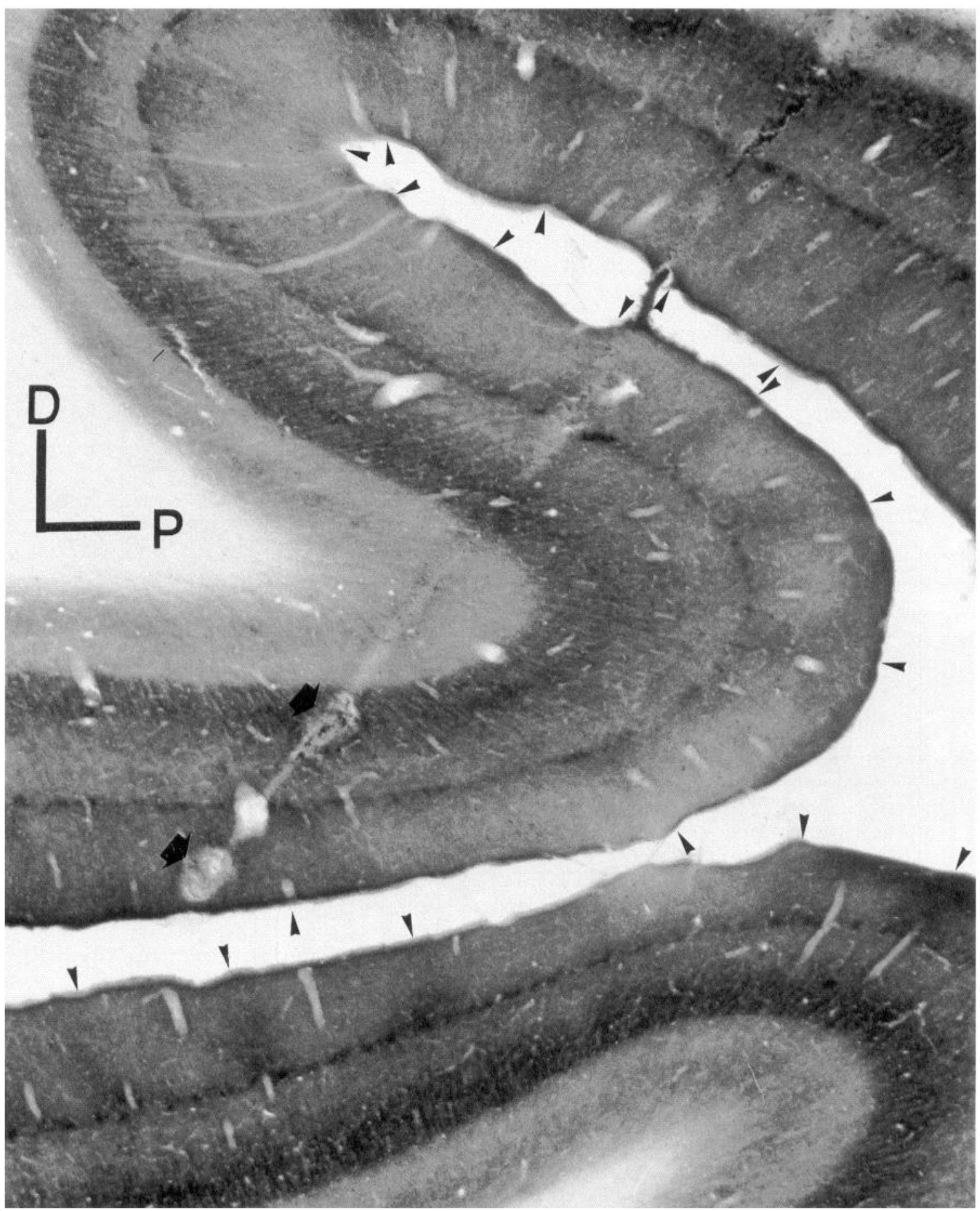

Figure 9. Cytochrome oxidase-stained section through V1. A photomicrograph of a parasagittal section through the posterior portion of the calcarine sulcus is shown. Arrowheads in the lumen of the sulcus point to blobs that are visible at irregular spacing in the superficial layers. Because the section intersected blobs off-center, blobs vary considerably in their darkness and size. The electrode was inserted through the operculum (not visible) so that it passed through both banks of the dorsal limb of the head of the calcarine sulcus (upper right), and then continued into the dorsal bank of the stem of the calcarine sulcus (lower left). Two large arrows point to electrolytic lesions that were made near the end of the penetration. The axes indicating dorsal $(D)$ and posterior $(P)$ directions have a length corresponding to $400 \mu \mathrm{m}$.

nonoptimal orientations. It would be particularly interesting to characterize thoroughly the response properties of neurons that receive selective or mixed input.

Relative strengths of parvocellular and magnocellular contributions. There are several reasons why the amount of reduction of response following selective $\mathrm{LGN}$ inactivation cannot be taken as a complete indication of the relative contribution of the blocked subdivision. Important among these is the fact that responses at each V1 site were measured using a single stimulus. Parvocellular and magnocellular neurons have different stimulus se- 

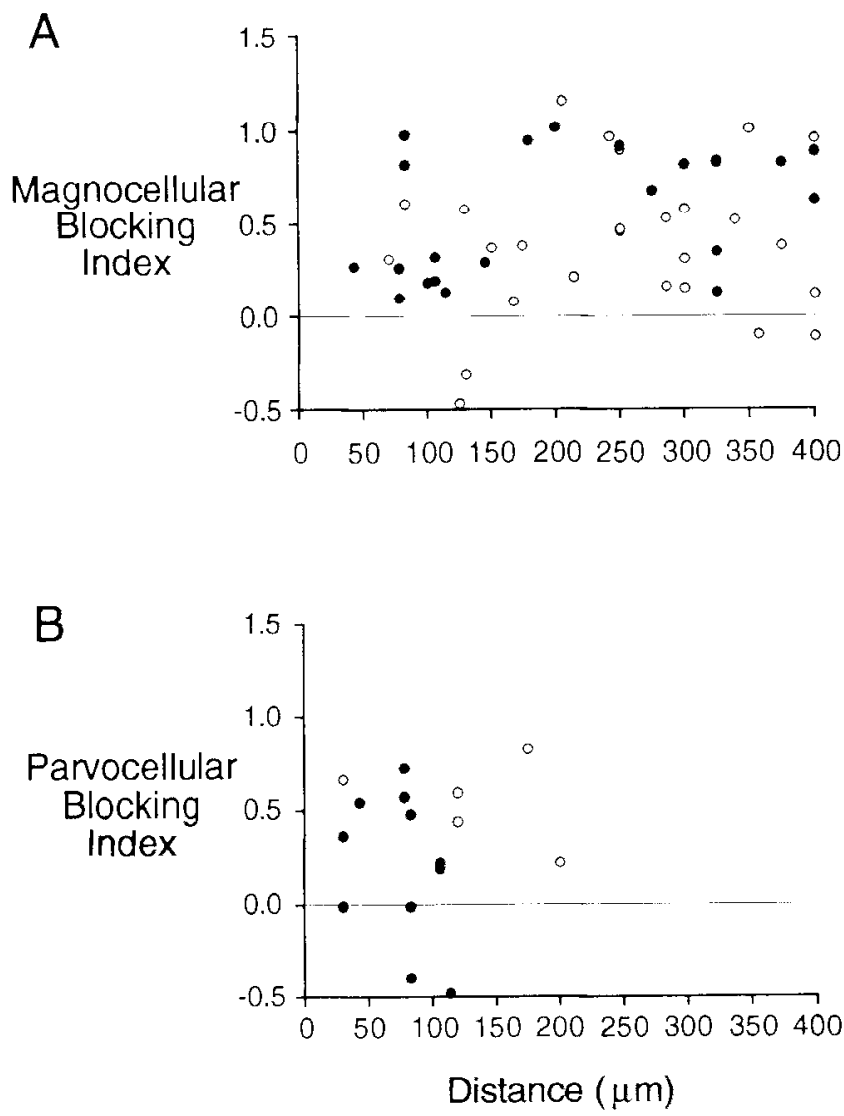

Figure 10. Relationship of blocking index to distance of V1 site from the nearest blob center. Solid circles cortespond to single units; open circles correspond to multiunit sites. The upper panel plots magnocellular blocking indices for 50 superficial V 1 sites that were no more than $400 \mu \mathrm{m}$ from the nearest blob center. The lower panel plots parvocellular blocking indices for all superficial sites tested with parvocellular block. There is no evidence for magnocellular contributions being preferentially distributed to either the blobs or interblobs.

lectivities, and if measurements were made using a stimulus that greatly favored one class or the other, cortical responses could be expected to depend primarily on the favored cells. The stimuli we used were selected to stimulate optimally the VI site being recorded. They invariably had high contrast and drove both LGN subdivisions strongly. We therefore belicve that the tests did not favor either subdivision, and that the results are representative of stimuli that would exist in everyday visual scenes. Nevertheless, it is virtually certain that different results would obtain if the tests had been performed with different stimuli, such as isoluminant color borders or low-contrast stimuli.

Another technical consideration is the possibility that the range of eccentricities tested $\left(17-24^{\circ}\right)$ may not be representative for all of $\mathrm{V} 1$. Although the ratio of $\mathrm{M}$ to $\mathrm{P}$ cells in the retina appears to be relatively constant from $10^{\circ}$ to $50^{\circ}$ eccentricity (Perry et al., 1984), about hall of V1 (and other topographically organized visual areas) represents cccentricitics more central than $10^{\circ}$, where the ratio has proven difficult to determine. It appears likely that the ratio of parvoccllular and magnocellular innervation in V1 will follow the ratio of ganglion cells in the retina, but this has been disputed (see Livingstone and Hubel, $1988 \mathrm{~b}$ ). The question of whether the relative contributions of
A: Magno Block

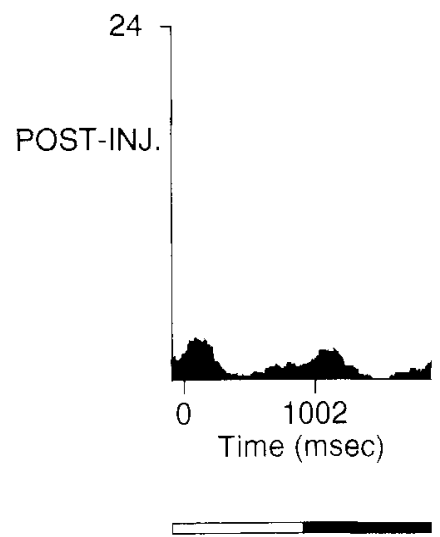

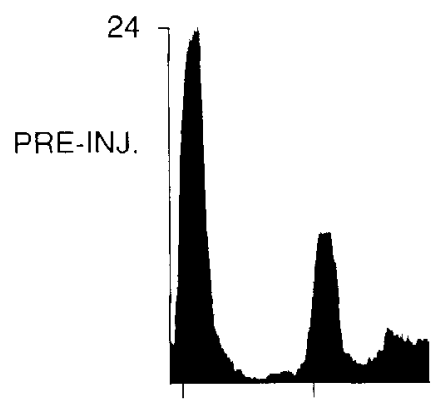

B: Parvo Block

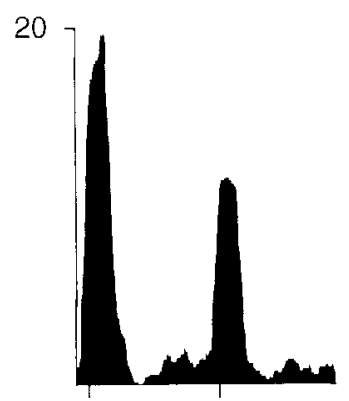

20

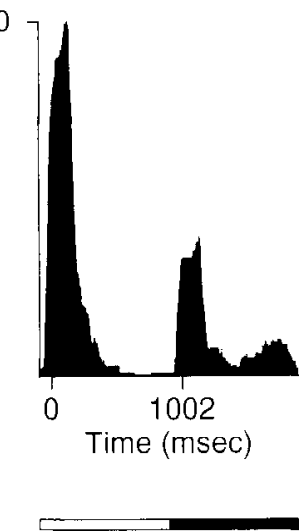

Figure 11. Example of an almost pure magnocellular contribution to a V1 neuron within a blob. The preinjection and postinjection histograms for a $V 1$ single unit tested with magnocellular and parvocellular block are shown. following the conventions of earlier examples. A, The pre- and postinjection histograms for magnocellular block. The BI was 0.98 . indicating virtually complete removal of the preinjection response. $B$, The pre- and postinjection histograms for the same neuron tested with parvocellular block. The BI was -0.04 , indicating Ininimal effect of parvocellular block on the response and confirming an isolated magnocellular contribution to the response of the neuron. The neuron was recorded within a cytochrome oxidase blob, $80 \mu \mathrm{m}$ from its center.

magnocellular and parvocellular inputs varies with eccentricity must for the present remain open.

Finally, it is important to recognize that even under a fixed stimulus condition the total response of a neuron is not likely to be the lincar sum of its magnocellular and parrocellular in-

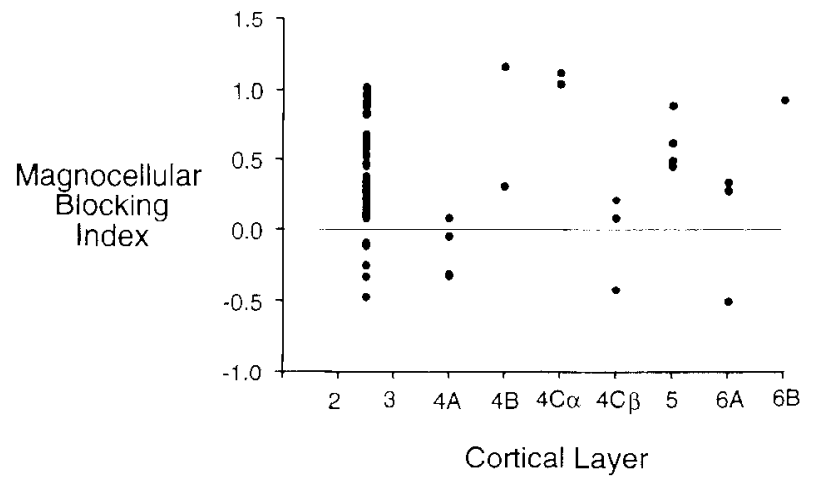

Figure 12. Magnocellular BIs measured in different cortical layers. Bls for all sites that could be unequivocally assigned to a layer are plotted. The mean magnocellular blocking indices in layers 4 and below reflect known contributions of magnocellular LGN to layers $4 \mathrm{~B}, 4 \mathrm{C} \alpha$, and $6 \mathrm{~B}$. As expected sites in layers $4 A$ AC $B$, and $6 \mathrm{~A}$ showed little magnocellular contribution. 
puts. Without knowing the nature and extent of nonlinear interactions between the two pathways it is impossible to relate the proportion of the cortical response that is eliminated by blocking one LGN subdivision to the proportion of excitatory drive that derives from that pathway. Put another way, there is little reason to think that the magnocellular and parvocellular BIs for a unit should add to one. The average for the sum of magnocellular and parvocellular BIs for the units that were tested for both was actually 0.45 . If we accept that most of the excitatory drive in $\mathrm{V} 1$ derives from the LGN, this result suggests that there is a partial compensation when one input is removed (a gain control), and that the BI generally underestimates the relative contribution to excitatory drive.

Interlaminar neurons in the $L G N$. Discussion of the retinocortical pathway in primates often focuses on the magnocellular and parvocellular neurons of the LGN, ignoring the other visual neurons in that nucleus. The macaque LGN contains a third class of cells in the S layers and interlaminar zones, which together are designated the koniocellular neurons. The $S$ layers lie ventral to the magnocellular layers. They contain a sparse population of neurons and are poorly characterized, but they have been shown to comprise two layers that each receive innervation from one eye (Kaas et al., 1978). The interlaminar neurons are small cells lying primarily between the two magnocellular layers and the magnocellular/parvocellular border, but also between the parvocellular layers (Kaas et al., 1978). These koniocellular neurons were almost certainly affected by the GABA injections, and might have contributed to the changes in responses that we recorded in cortex. It is therefore important to consider how significant their contribution is likely to be.

It could be argued that all of the responses in the superficial layers that we attributed to magnocellular contributions arose instead from koniocellular neurons that were inactivated when the inagnocellular layers were blocked. This is unlikely for several reasons. V1 neurons with robust magnocellular inputs in layers $4 \mathrm{C} \alpha$ and $4 \mathrm{~B}$ send strong, direct connections to the superficial layers (Blasdel et al., 1985; Fitzpatrick et al., 1985; Lachica et al., 1992), while the koniocellular projection to V1 is relatively weak (Livingstone and Hubel, 1982). For corresponding reasons we think it is unlikely that the effects of injecting the parvocellular layers resulted from block of the koniocellular neurons in that subdivision. The most plausible view of the present experiments is that our magnocellular injections block all magnocellular activity and much, but not all, of the koniocellular activity, and that our parvocellular injections blocked all parvocellular activity and some koniocellular activity.

\section{References}

Blasdel GG, Lund JS (1983) Termination of afferent axons in macaque striate cortex. J Neurosci 3:1389-1413.

Blasdel GG, Lund JS, Fitzpatrick D (1985) Intrinsic connections of macaque striate cortex: axonal projections of cells outside lamina $4 \mathrm{C}$. J Neurosci 5:3350-3369.

Casagrande VA, Norton TT (1991) Lateral geniculate nucleus: a review of its physiology and function. In: The neural basis of visual function (Leventhal A, ed), pp 41-84. London: Macmillan.

Connolly M, Van Essen DC (1984) The representation of the visual field in parvicellular and magnocellular layers of the lateral geniculate nucleus in the macaque monkey. J Comp Neurol 226:544-564.

DeYoe EA, Sesola LC (1991) Distinct pathways link anatomical subdivisions of V4 with V2 and temporal cortex. Soc Neurosci Abstr 17: 1282.

DeYoe EA, Van Essen DC (1985) Segregation of efferent connections and receptive field properties in visual area V 2 of the macaque. Nature 317:58-61.

DeYoe EA, Van Essen DC (1988) Concurrent processing streams in monkey visual cortex. Trends Neurosci 11:219-226.

Felleman DJ, McClendon E (1991) Modular connections between area V4 and temporal lobe area PITv in macaque monkeys. Soc Neurosci Abstr 17:1282.

Ferrera VP, Nealey TA, Maunsell JHR (1992) Mixed parvocellular and magnocellular geniculate signals in visual area V4. Nature 358 : 756-758.

Ferrera VP, Nealey TA, Maunsell JHR (1994) Responses in macaque visual area $\mathrm{V} 4$ following inactivation of the parvocellular and magnocellular LGN pathways. J Neurosci 14:2080-2088.

Fitzpatrick D, Einstein G (1989) Laminar distribution and morphology of area 17 neurons projecting to the lateral geniculate nucleus in the macaque. Soc Neurosci Abstr 15:1398.

Fitzpatrick D, Lund JS, Blasdel GG (1985) Intrinsic connections of macaque striate cortex: afferent and efferent connections of lamina 4C. J Neurosci 5:3329-3349.

Fries W (1986) Distribution of Meynert cells in primate striate cortex. Naturwissenschaften 73:557-558.

Hendrickson AE, Wilson JR, Ogren MP (1978) The neuroanatomical organization of pathways between the dorsal lateral geniculate nucleus and visual cortex in Old World and New World primates. I Comp Neurol 182:123-136.

Horton JC, Hubel DH (1981) Regular patchy distribution of cytochrome oxidase staining in primary visual cortex of macaque monkey. Nature 292:762-764.

Hubel DH, Livingstone MS (1987) Segregation of form, color, and stereopsis in primate area 18 . J Neurosci 7:3378-3415.

Hubel DH, Livingstone $M$ (1990) Color and contrast sensitivity in the lateral geniculate body and primary visual cortex of the macaque monkey. J Neurosci 10:2223-2237.

Hubel DH, Wiesel TN (1972) Laminar and columnar distribution of geniculo-cortical fibers in macaque monkeys. J Comp Neurol 146: $421-450$.

Hübener M, Bolz J (1991) Cell morphology and blob pattern in monkey striate cortex. Soc Neurosci Abstr 17:117.

Irvin GE, Norton TT, Sesma MA, Casagrande VA (1986) W-like response properties of interlaminar zone cells in the lateral geniculate nucleus of a primate (Galago crassicaudatus). Brain Res 362:254270.

Kaas JH, Huerta MF, Weber JT, Harting JK (1978) Patterns of retinal tcrminations and laminar organization of the lateral geniculate nucleus of primates. J Comp Neurol 182:517-554.

Krubitzer LA, Kaas JH (1989) Cortical integration of parallel pathways in the visual system of primates. Brain Res 478:161-165.

Lachica EA, Beck PD, Casagrande VA (1992) Parallel pathways in macaque monkey striate cortex: anatomically defined columns in layer III. Proc Natl Acad Sci USA 89:3566-3570.

Livingstone MS, Hubel DH (1982) Thalamic inputs to cytochrome oxidase-rich regions in monkey visual cortex. Proc Natl Acad Sci USA 79:6098-6101.

Livingstone MS, Hubel DH (1984a) Anatomy and physiology of a color system in the primate visual cortex. J Neurosci 4:309-356.

Livingstone MS, Hubel DH (1984b) Specificity of intrinsic connections in primate primary visual cortex. J Neurosci 4:2830-2835.

Livingstone M, Hubcl D (1987a) Conncctions between layer 4B of area 17 and thick cytochrome oxidase stripes of area 18 in the squirrel monkey. J Neurosci 7:3371-3377.

Livingstone M, Hubel D (1987b) Psychophysical evidence for separate channels for the perception of form, color, movement and depth. J Neurosci 7:3416-3468

Livingstone M, Hubel D (1988a) Segregation of form, color, movement, and depth: anatomy, physiology and perception. Science 240 : $740-749$.

Livingstone MS, Hubel DH (1988b) Do the relative mapping densities of the magno- and parvocellular systems vary with eccentricity? $\mathrm{J}$ Neurosci $8: 4334-4339$

Lund JS, Boothe RG (1975) Interlaminar connections and pyramidal neuron organisation in the visual cortex, area 17, of the macaque monkey. J Comp Neurol 159:305-334.

Lund JS, Lund RD, Hendrickson AE, Bunt AH, Fuchs AF (1976) The origin of efferent pathways from the primary visual cortex, area 17 , of the macaque monkey. J Comp Neurol 164:287-304.

Lund JS, Henry GH, MacQueen CL, Harvey AR (1979) Anatomical 
organization of the primary visual cortex (area 17) of the cat: a comparison with area 17 of the macaque monkey. J Comp Neurol 184: 599-618.

Malach R (1992) Dendritic sampling across processing streams in monkey striate cortex. J Comp Neurol 315:303-312.

Malpeli JG, Baker FH (1975) The representation of the visual field in the lateral geniculate nucleus of Macaca mulatta. J Comp Neurol 161:569-594.

Malpeli JG, Schiller PH (1979) A method of reversible inactivation of small regions of brain tissue. J Neurosci Methods 1:143-157.

Malpeli JG, Schiller PH, Colby CL (1981) Response properties of single cells in monkey striate cortex during reversible inactivation of individual lateral geniculate laminae. J Neurophysiol 46:1102-1119.

Maunsell JHR (1987) Physiological evidence for two visual subsystems. In: Matters of intelligence (Vaina L, ed), pp 59-87. Dordrecht: Reidel.

Maunsell JHR, Newsome WT (1987) Visual processing in monkey extrastriate cortex. Annu Rev Neurosci 10:363-401

Maunsell JHR, Van Essen DC (1983) Functional properties of neurons in middle temporal visual area of the macaque monkey. I. Selectivity for stimulus direction, speed, and orientation. J Neurophysiol 49: $1127-1147$.

Maunsell JHR, Nealey TA, DePriest DD (1990) Magnocellular and parvocellular contributions to responses in the middle temporal visual area (MT) of the macaque monkey. J Neurosci 10:3323-3334.

Maunsell JHR, Nealey TA, Ferrera VP (1992) Magnocellular and parvocellular contributions to neuronal responses in monkey visual cortex. Invest Ophthalmol Vis Sci 33:901.

Merigan WH, Eskin TA (1986) Spatio-temporal vision of macaques with severe loss of $P_{k}$ retinal ganglion cells. Vision Res 26:1751-1761.

Merigan WH, Maunsell JHR (1993) How parallel are the primate visual pathways? Annu Rev Neurosci 16:369-402

Motter BC, Mountcastle VB (1981) The functional properties of the light-sensitive neurons of the posterior parietal cortex studied in awake monkeys: foveal sparing and opponent vector organization. J Neurosci 1:3-26.

Nealey TA, Maunsell JHR (1991) Magnocellular contributions to the superficial layers of macaque striate cortex. Invest Ophthalmol Vis Sci 32:1117

Nealey TA, Ferrera VP, Maunsell JHR (1991) Magnocellular and parvocellular contributions to the ventral extrastriate cortical processing stream. Soc Neurosci Abstr 17:525.
Norton TT, Casagrande VA (1982) Laminar organization of receptiveficld properties in the lateral geniculate nucleus of bushbaby (Galago crassicaudatus). J Neurophysiol 47:715-741.

Payne BR, Peters A (1989) Cytochrome oxidase patches and Meynert cells in monkey visual cortex. Neuroscience 28:353-363.

Perry VH, Ochler R. Cowey A (1984) Retinal ganglion cells that project to the dorsal lateral geniculate nucleus in the macaque monkey. Neuroscience 12:1101-1123.

Schiller PH, Malpeli JG (1978) Functional specificity of lateral geniculate nucleus laminae of the rhesus monkey. I Neurophysiol 41:788797.

Schiller PH, Malpeli JG, Schein SJ (1979) Composition of geniculostriate input to superior colliculus of the rhesus monkey. J Neurophysiol 42:1124-1133.

Shaw C, Cynader M (1986) Laminar distribution of receptors in monkey (Macaca fascicularis) geniculostriate system. J Comp Neurol 248 $301-312$

Shipp S, Zcki S (1985) Segregation of pathways leading from area V2 to areas $\mathrm{V} 4$ and $\mathrm{V} 5$ of macaque monkey visual cortex. Nature 315 $322-325$

Silverman M, Tootell RBH (1987) Modified technique for cytochrome oxidase histochemistry: increased staining intensity and compatibility with 2-deoxyglucose autoradiography. J Neurosci Methods 19:1-10.

Tootell RBH, Hamilton SL, Switkes E (1988) Functional anatomy of macaque striate cortex. IV. Contrast and magno-parvo streams. J Neurosci 8:1594-1609.

Ungerleider LG, Mishkin M (1982) Two cortical visual systems. In: Analysis of visual behavior (Ingle DJ, Goodale MA, Mansfield RJW, eds), pp 549-585. Cambridge, MA: MIT Press.

Van Essen DC, Maunsell JIIR (1983) Hierarchical organization and functional streams in the visual cortex. Trends Neurosci 6:370-375.

Watson AB (1992) Transfer of contrast sensitivity in linear visual networks. Vis Neurosci 8:65-76.

Wong-Riley M, Carroll EW (1984) Effect of impulse blockage on cytochrome oxidase activity in monkey visual system. Nature 307:262264.

Zrenner E, Zbramov I, Akita M, Cowey A, Livingstone M, Valberg A (1990) Color perception: retina to cortex. In: Visual perception: the neurophysiological foundations (Spillmann L, Werner JS, eds), pp 163-204. New York: Academic. 